\title{
X-Band GaN High-Power Amplifier Using Hybrid Power Combining Technique for SAR Applications
}

\section{Yun-Jui Lee', Chi-Yang Chang'1, Young-Huang Chou', I-Young Tarn², James Yu-Chen Yaung', Jenn-Hwan Tarng ${ }^{1,3}$, and Shyh-Jong Chung ${ }^{1}$}

\author{
${ }^{1}$ Institute of Communications Engineering, National Chiao-Tung University (NCTU), Hsinchu, Taiwan (R.O.C.) \\ ${ }^{2}$ National Space Organization (NSPO), National Applied Research Laboratories (NARLabs), Hsinchu, Taiwan (R.O.C.) \\ ${ }^{3}$ Center for mmWave Smart Radar Systems and Technologies, National Chiao-Tung University, Hsinchu, Taiwan (R.O.C.) \\ *corresponding author, E-mail: uraylee@gmail.com
}

\begin{abstract}
An X-band high-power amplifier (HPA) based on gallium nitride $(\mathrm{GaN})$ high electron mobility transistors (HEMTs) has been developed for synthetic aperture radar (SAR) applications. A hybrid power combining technique, including microstrip circuits and waveguides, is used to design the HPA. For reducing the size, four $50 \mathrm{~W}$ GaN HEMTs cascaded with one 1-to-4 power divider and one 4to-1 power combiner form a 4-way power combined PCB circuits. For combing the high power and driving an antenna, two PCB circuits are combined by magic-T waveguides. The transmission efficiency of the power combining is approximately $80 \%$. In the $10 \%$ duty cycle (pulse width 100 us), the output power of the HPA is over $200 \mathrm{~W}$ across the band of 9.5-9.8 GHz. The maximum output power is $230 \mathrm{~W}$ at $9.5 \mathrm{GHz}$, and the power gain is $8.3 \mathrm{~dB}$ at $46.1^{\circ} \mathrm{C}$.
\end{abstract}

\section{Introduction}

An RF power amplifier plays an important role in many radio transmitters. It is used to convert a low power signal into a high power signal to feed the antenna of transmitters. Because of the required power higher than $1 \mathrm{KW}$, traveling wave tube amplifiers (TWTAs) have been utilized for many radar systems, such as weather radar, synthetic aperture radar (SAR), and so on. However, it is pointed out that TWTAs have high maintenance costs due to their short lifetime, occupy significant area, and have large weight [1]. Hence, there is a strong desire for solid-state power amplifiers (SSPAs) that are superior in long-term reliability and serviceability to replace conventional TWTAs.

In the decade, SSPAs using gallium nitride $(\mathrm{GaN})$ high electron mobility transistors (HEMTs) are reported in [210]. A GaN HEMT is attractive for high power applications due to particular capabilities such as high output power, great efficiency, and smaller parasitic capacitances. Moreover, it is capable of covering wide bandwidth because of its high input and output impedance. Nowadays, engineers pay attention to design micro satellites (10-100 $\mathrm{Kg}$ ) for reducing the production costs and launch them into the space easily. A key enabling technique for SAR applications is using hybrid high power combining based on GaN HEMTs. This topology provides large power, compact size, wideband performance, and light weight. After the technique is developed successfully, TWTAs on the satellites can be replaced by $\mathrm{GaN}$ high-power amplifiers (HPAs).

In [5], a 4-way power combiner with isolators is used to combine four $80 \mathrm{~W}$ GaN HEMTs. The low isolation between nearby ports makes the isolators needed and the size large. In [6], the performance of a coaxial waveguide spatial power combining structure is good for large-scale power combing over multi-octave bandwidths. In this paper, we propose a GaN HPA using hybrid power combining technique. It is composed of eight GaN HEMTs with PCB circuits and two magic-T waveguides for size reduction and high power handling. The GaN HPA is operated from 9.5 to 9.8 $\mathrm{GHz}$ for SAR applications.

\section{Design of the GaN high-power amplifier}

\subsection{Block diagram of the amplifier}

The block diagram of the proposed X-band GaN high-power amplifier is shown in Fig. 1. It consists of a pre-amplifier and a main amplifier. We use a hybrid power combining technique to design the main amplifier. To make the device compact, eight $50 \mathrm{~W}$ GaN HEMTs are combined by

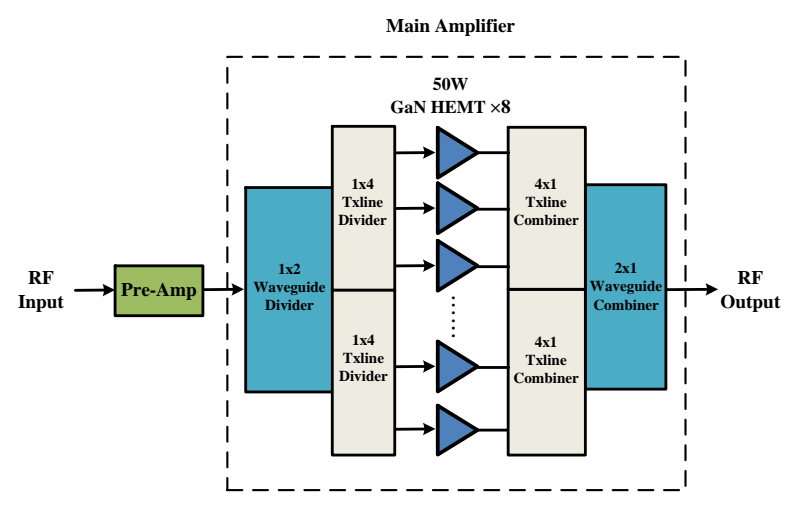

Figure 1: Block diagram of the proposed X-band GaN high-power amplifier. 
microstrip circuits. To combine high output power and connect to an antenna, low-loss waveguides are utilized.

\subsection{Main Amplifier}

Fig. 2 shows the corresponding geometry of the proposed main amplifier. In Fig. 2(a), 1-to-2/ 2-to-1 power dividers/combiners are designed by magic-T waveguides. 1to-4/4-to-1 power dividers/combiners are made by three branch-line couplers. Four $50 \mathrm{~W}$ GaN HEMTs cas caded

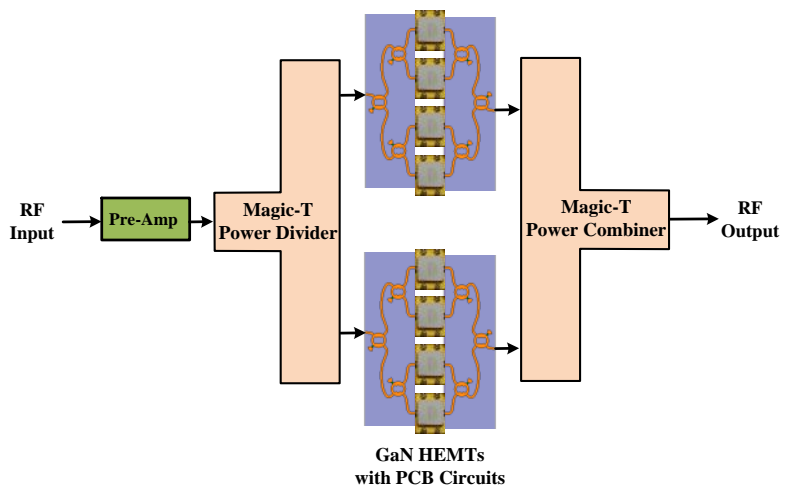

(a) Block diagram

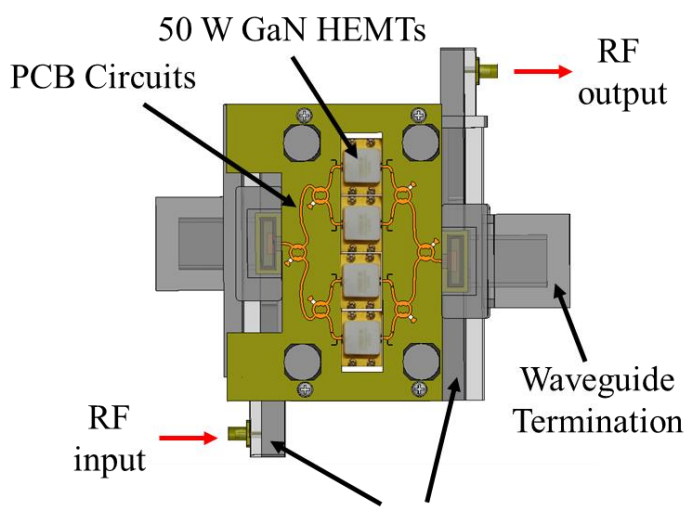

Magic-T Waveguides

(b) Side view

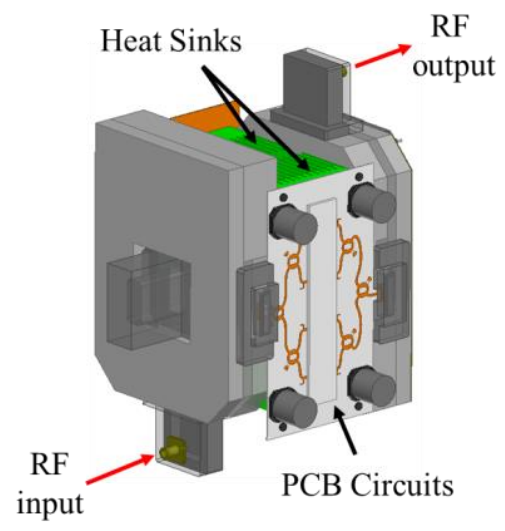

(c) $3 \mathrm{D}$ view

Figure 2: Geometry of the proposed X-band GaN highpower amplifier. with one 1-to-4 power divider and one 4-to-1 power combiner become a 4-way power combined PCB circuits. Moreover, two PCB circuits mounted on each side of heat sinks are combined by magic- $\mathrm{T}$ waveguides and cooled by air blasts. The geometry of hybrid 8-way high power combining is illustrated in Fig. 2(b)(c). Commercial CREE GaN HEMTs are used in the HPA design [11]. The measured reflection coefficient of the GaN HEMT is $-5 \mathrm{~dB}$. The measured results of the output power and the power gain are shown in Fig. 3. The operated drain voltage is $40 \mathrm{~V}$ and the drain current is approximately $0.4 \mathrm{~A}$ at $35^{\circ} \mathrm{C}$.

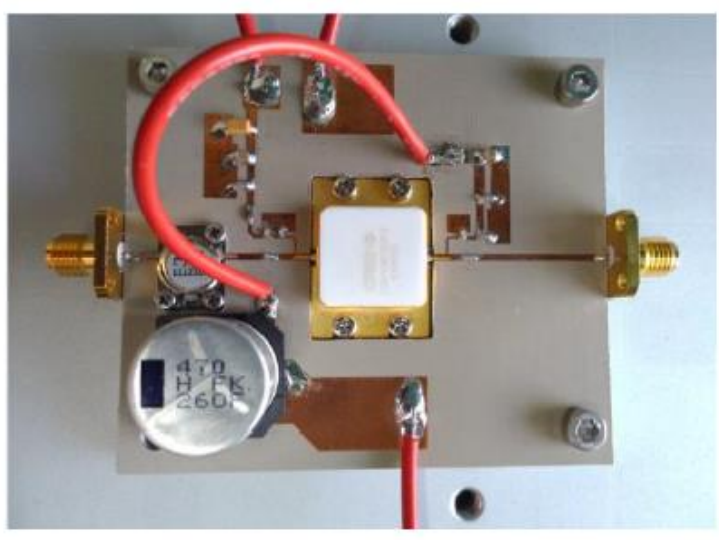

(a) Photo of the GaN HEMT

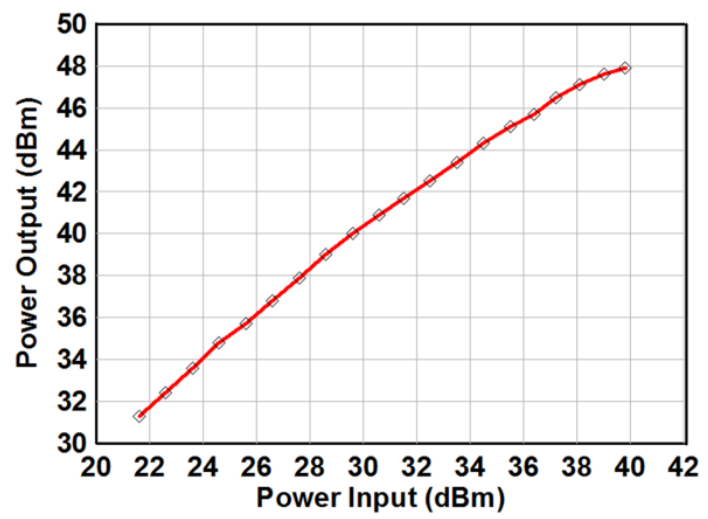

(b) Input power vs output power

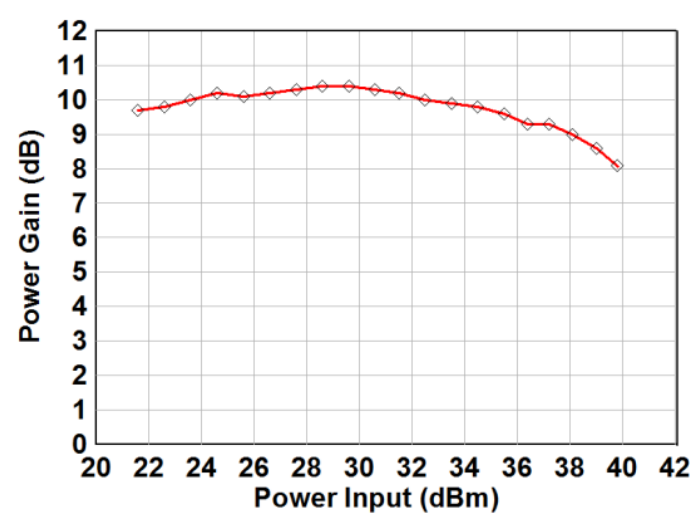

(c) Input power vs power gain

Figure 3: Measured results of the $50 \mathrm{~W}$ GaN HEMT 


\subsubsection{4-to-1 Power Combiner}

A 4-to-1 power combiner composed of three branch-line couplers in two stages is shown in Fig. 4. The couplers are designed in circle shapes in order to reduce transmission losses. The 4-to-1 power combiner is printed on a single piece of Taconic RF35 substrate demonstrating a dielectric constant $\left(\varepsilon_{r}\right)$ of 3.5 and thickness of 20 mil. Fig. 5 illustrates the simulated and measured results of the 4-to-1 power combiner. In Fig. 5(a), the reflection coefficient is below $-20 \mathrm{~dB}$ and the insertion loss is about $-7.3 \mathrm{~dB}$ from 9.5 to $9.8 \mathrm{GHz}$. The isolation among output ports is greater than 25 $\mathrm{dB}$ in Fig. 5(b). Due to some effect of fabrication, SMA connectors, and solders, the maximum variation of phase difference between nearby output ports is approximately 6

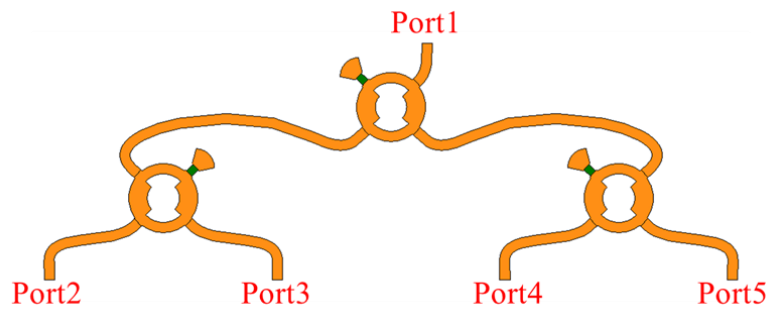

Figure 4: Geometry of the 4-to-1 power combiner.

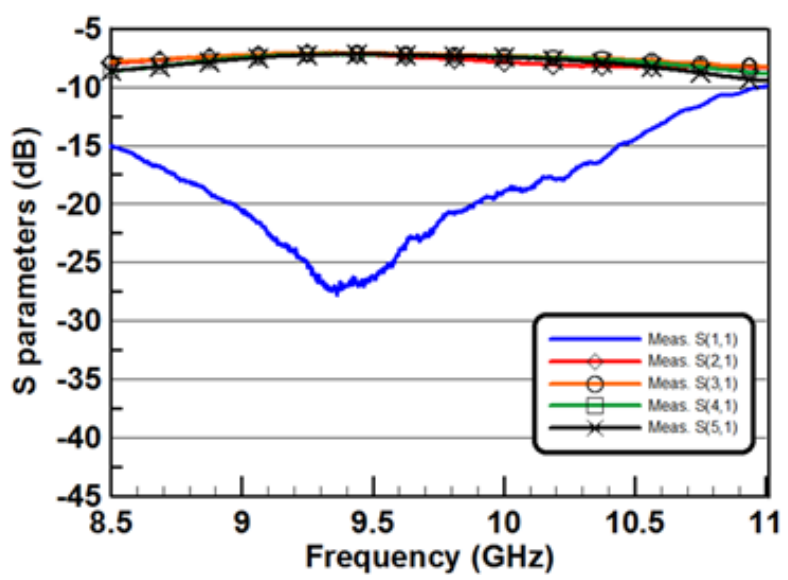

(a) Reflection and transmission coefficients

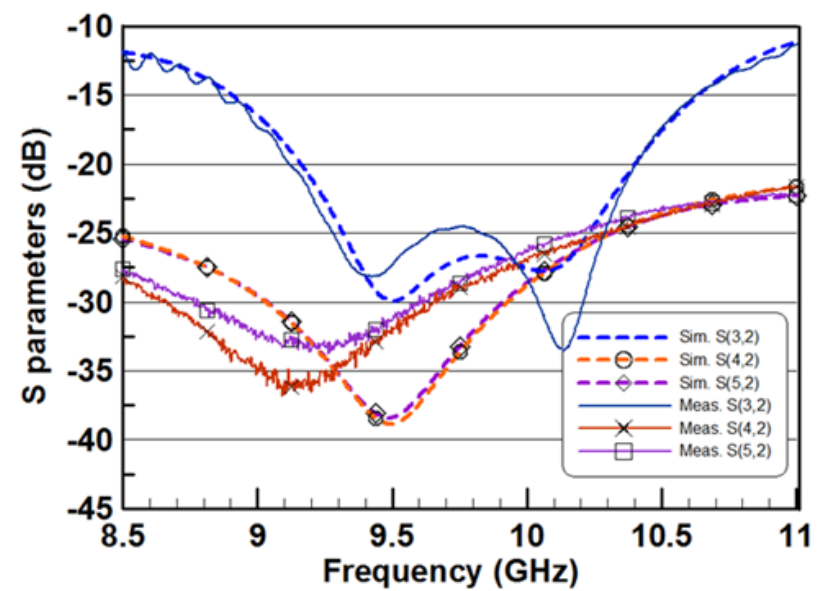

(b) Isolation among output ports

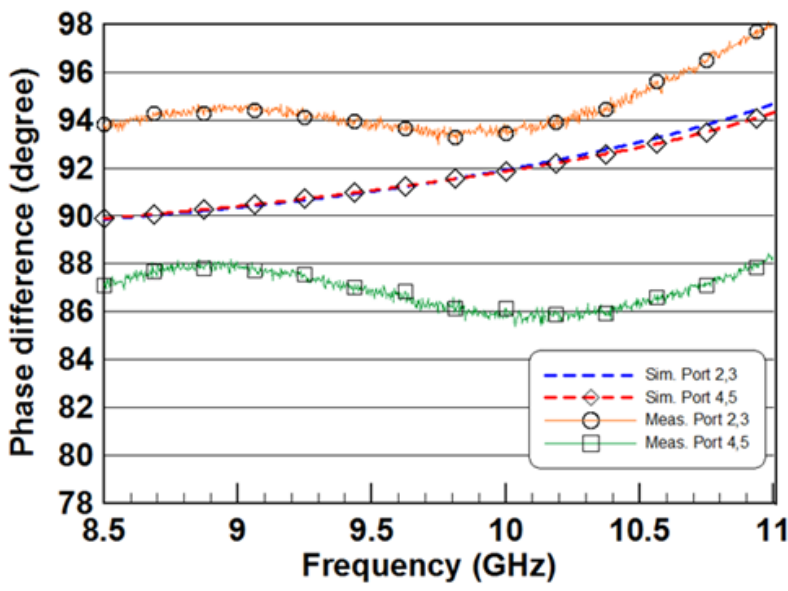

(c) Phase difference between nearby output ports

Figure 5: Simulated and measured results of the 4-to-1 power combiner.

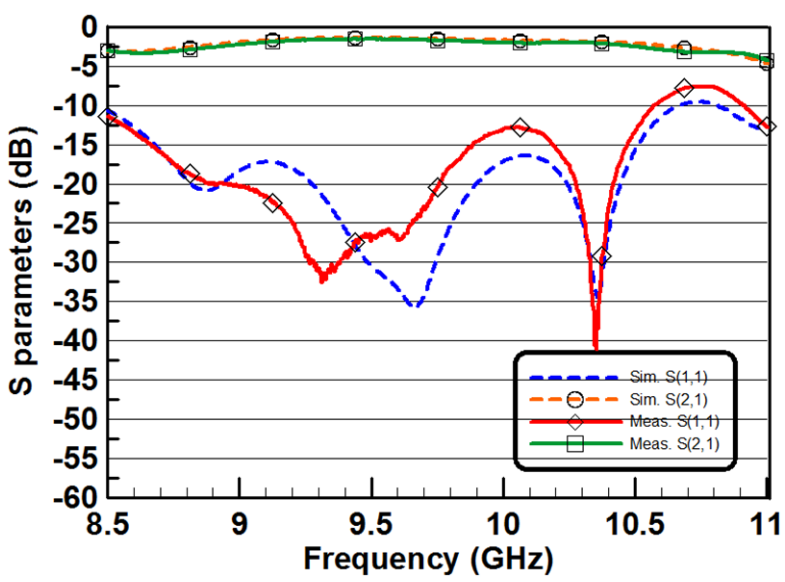

Figure 6: Simulated and measured results of the back-toback 4-to-1 power combiner.

between simulation and measurement results. Moreover, we use the method of back-to-back to measure the transmission efficiency of the 4-to-1 power combiner. In Fig. 6, the measured insertion loss is about $-1.7 \mathrm{~dB}$. Hence, the transmission efficiency of the 4-to-1 power combiner is approximately $82 \%$. The measured and simulated results are highly consistent.

\subsubsection{2-to-1 Power Combiner}

Fig. 7 illustrates a geometry of the 2-to-1 power combiner. It is made by a low-loss magic-T waveguide with a waveguide termination. Three SMA-to-waveguide adapters are designed for measurement. Fig. 8 shows the simulated results of the 2-to-1 power combiner with three SMA-towaveguide adapters. The reflection coefficients of three ports are lower than $-25 \mathrm{~dB}$. The insertion losses are approximately $-3.02 \mathrm{~dB}$ and the isolation is higher than 34 $\mathrm{dB}$. Moreover, the measured reflection coefficient is lower than $-23 \mathrm{~dB}$ and the insertion loss is approximately -3.13 

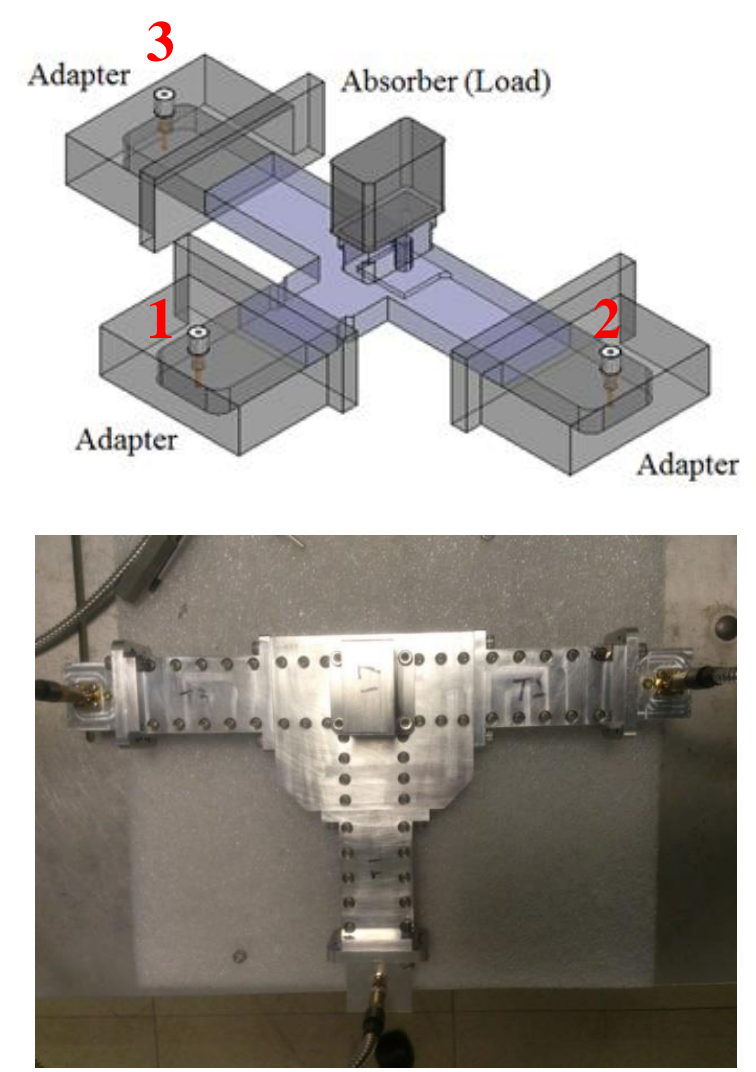

Figure 7: Geometry of the 2-to-1 power combiner.

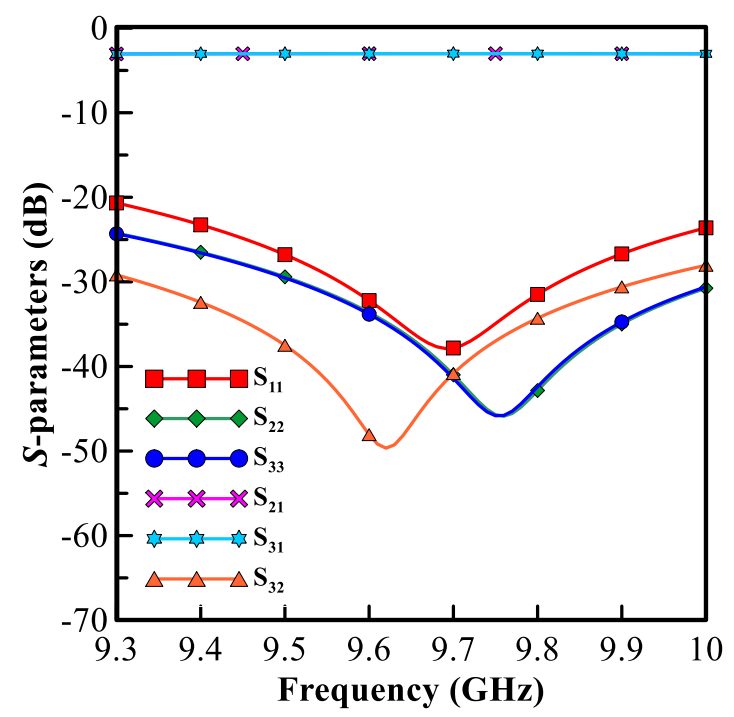

Figure 8: Simulated results of the 2-to-1 power combiner with three SMA-to-waveguide adapters.

dB. Hence, the transmission efficiency is higher than $99 \%$.

\subsubsection{Waveguide-to-Microstrip Transition}

Fig. 9 shows a structure of the waveguide-to-microstrip transition with a SMA-to-waveguide adapter. It is utilized to connect the 4-to-1 power combiner and the 2-to-1 power combiner. We design a back-to-back probe to measure the performance of the waveguide-to-microstrip transition as shown in Fig. 10. The measured reflection coefficient is lower than $-15 \mathrm{~dB}$ and insertion loss is $-0.5 \mathrm{~dB}$. Moreover, two waveguide-to-microstrip transitions with the back-toback 4-to-1 power combiner is plotted in Fig. 11. The simulated reflection coefficient is lower than $-25 \mathrm{~dB}$ and the insertion loss is $-1.6 \mathrm{~dB}$. Hence, the transmission efficiency of one waveguide-to-microstrip transition with a 4-to-1 power combiner is approximately $83 \%$.

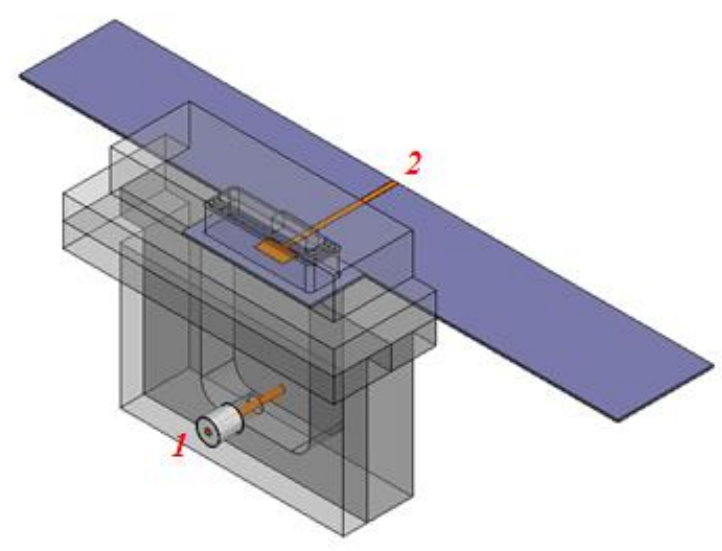

Figure 9: Structure of the waveguide-to-microstrip transition with a SMA-to-waveguide adapter.
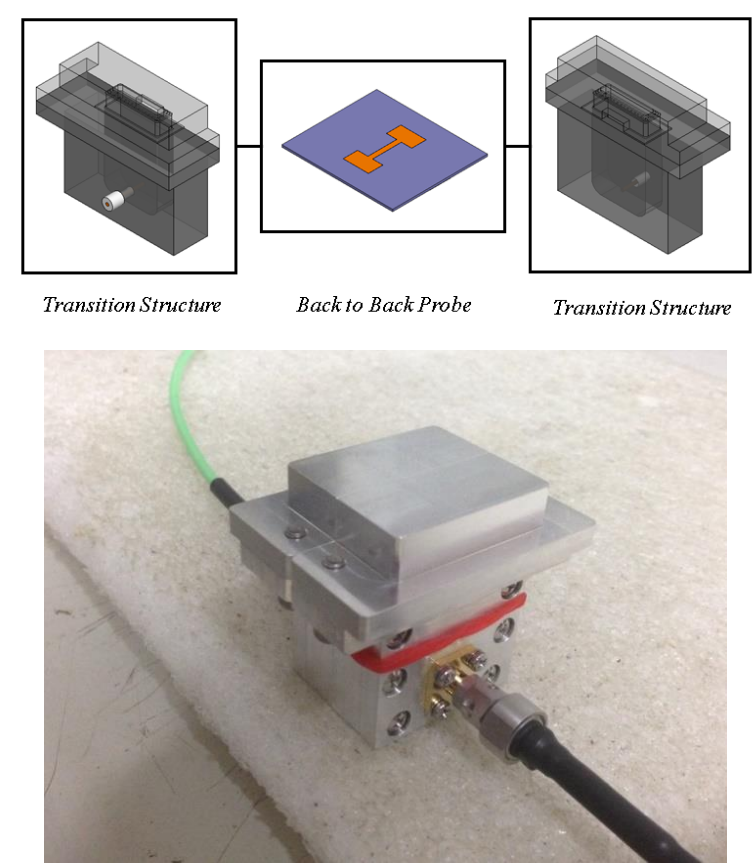

Figure 10: Photo of the back-to-back waveguide-tomicrostrip transitions. 


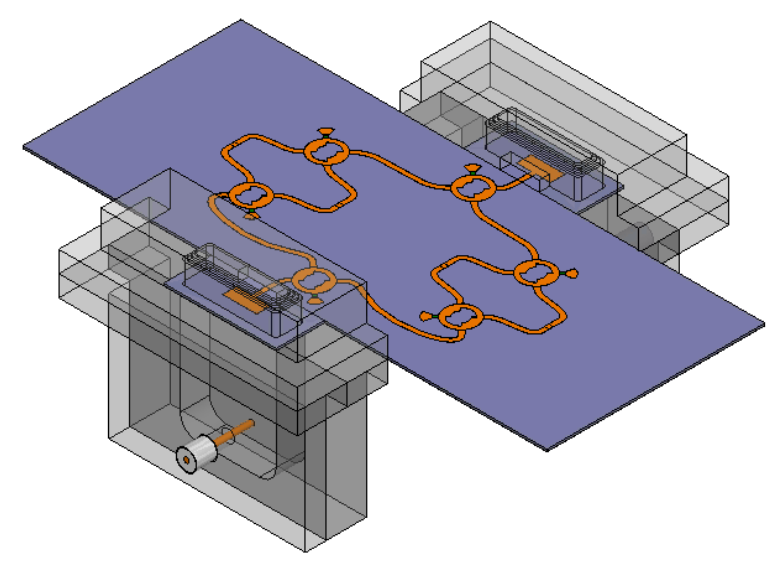

Figure 11: Waveguide-to-microstrip transitions with the back-to-back 4-to-1 power combiner.

\subsection{Module}

In the space, the power source is obtained from the solar panels. In our designed satellite, the supplied voltage of solar panels is $28 \mathrm{~V}$, which is different from that GaN HEMTs need. Hence, we have to design a DC module of the main amplifier, including DC-to-DC converters and regulators, to transform the voltages. A block diagram of the DC module is shown in Fig. 12. The positive voltage is obtained by using DC-to-DC converters with voltage divided circuits to convert $28 \mathrm{~V}$ to $40 \mathrm{~V}$. The negative voltage is got by utilizing a DC-to-DC converter (TPS84250) and a CMOS voltage converter (LMC7660) to convert $28 \mathrm{~V}$ to approximately $-2.7 \mathrm{~V}$.

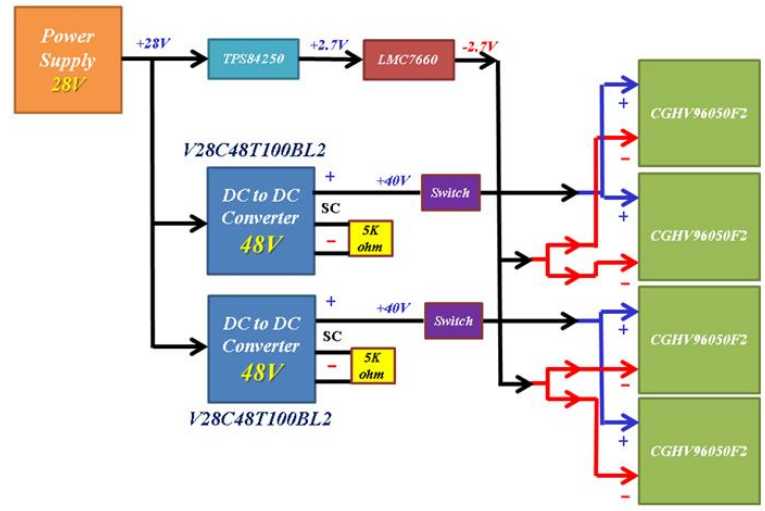

Figure 12: Block diagram of the DC module.

\section{Experimental results}

An equipment of X-band amplifier is used as the preamplifier. The accepted input power is $-5 \mathrm{dBm}$ and pushed upon for driving the main amplifier. Fig. 13 depicts the fabricated 2-to-1 and 4-to-1 power combiners with eight GaN HEMTs to form the X-band GaN high-power amplifier.

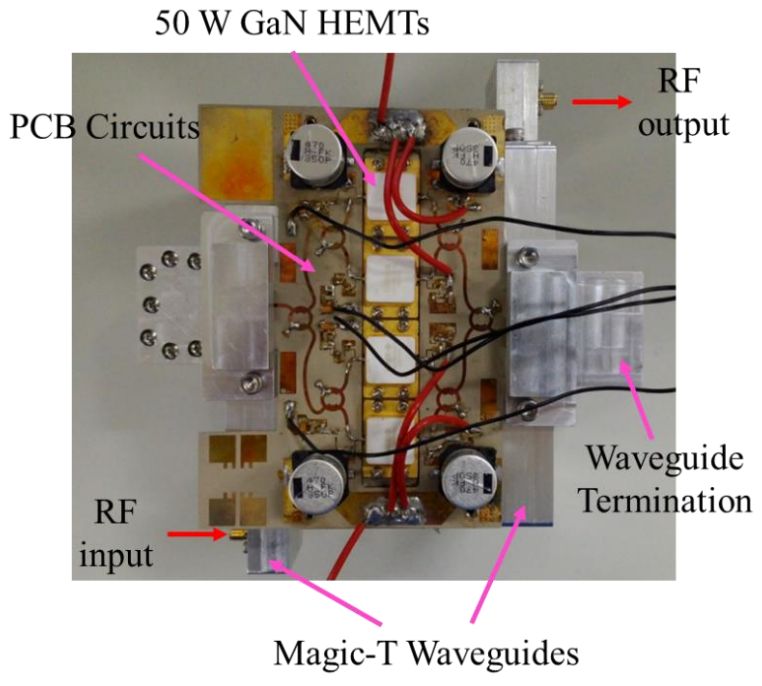

(a) Side view

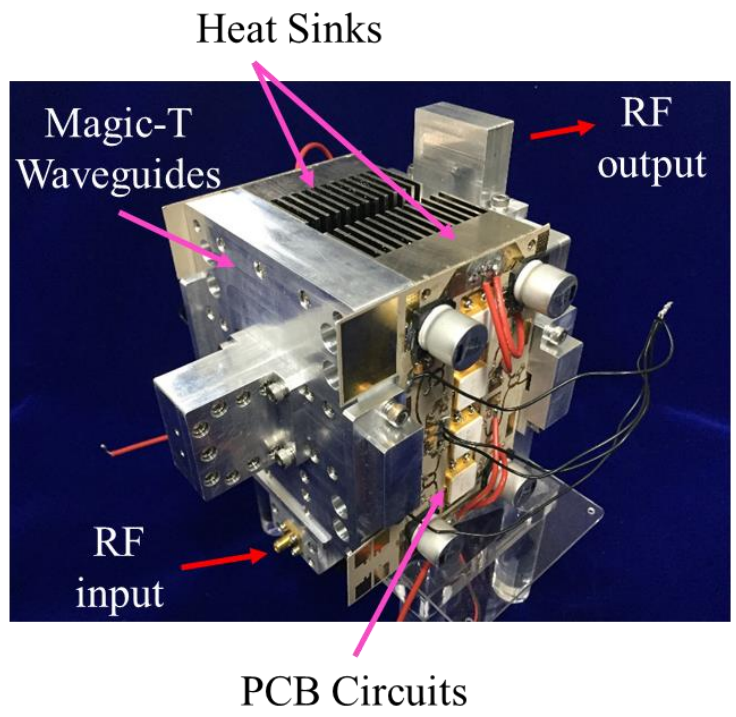

(b) 3D view

Figure 13: Photo of the proposed GaN high-power amplifier.

The RF input port is in the lower left. The overall size is approximately $19 \mathrm{~cm} \times 13.7 \mathrm{~cm} \times 17.7 \mathrm{~cm}$. The measured small signal parameters are plotted in Fig. 14. According to the low $S_{11}$ of the GaN HEMT, the measured reflection coefficient is higher than $-10 \mathrm{~dB}$ from 9.5 to $9.8 \mathrm{GHz}$. The gain is approximately $7.6 \mathrm{~dB}$ at $9.65 \mathrm{GHz}$. Fig. 15 shows the measured peak output power, power added efficiency (PAE), and power gain at $9.5,9.65,9.8 \mathrm{GHz}$, respectively. In the $10 \%$ duty cycle (pulse width $=100 \mathrm{us}$, period $=1 \mathrm{~ms}$ ), the maximum output power is $53.6 \mathrm{dBm}(230 \mathrm{~W})$ when the input power is $45.3 \mathrm{dBm}$ at $9.5 \mathrm{GHz}$ (The drain voltage is 40 $\mathrm{V}$ and the total drain current is $4.3 \mathrm{~A}$.). The power gain is 8.3 $\mathrm{dB}$ and the power added efficiency is $16.5 \%$ at $46.1^{\circ} \mathrm{C}$. Although much of the overall size is used for the heat sinks, 


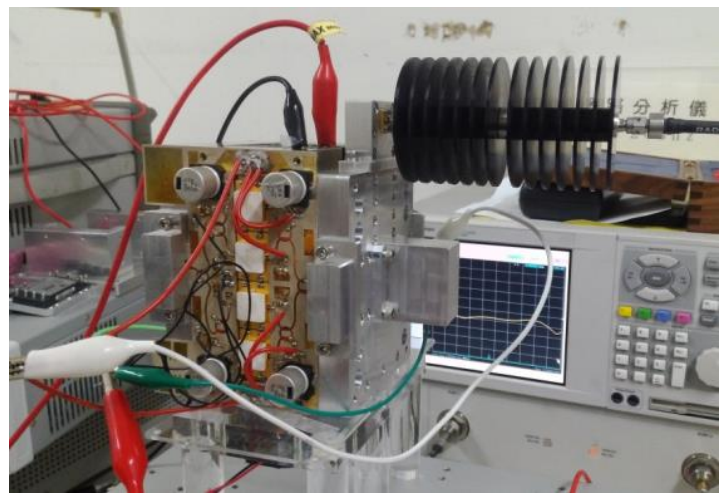

(a) Environment of measurement

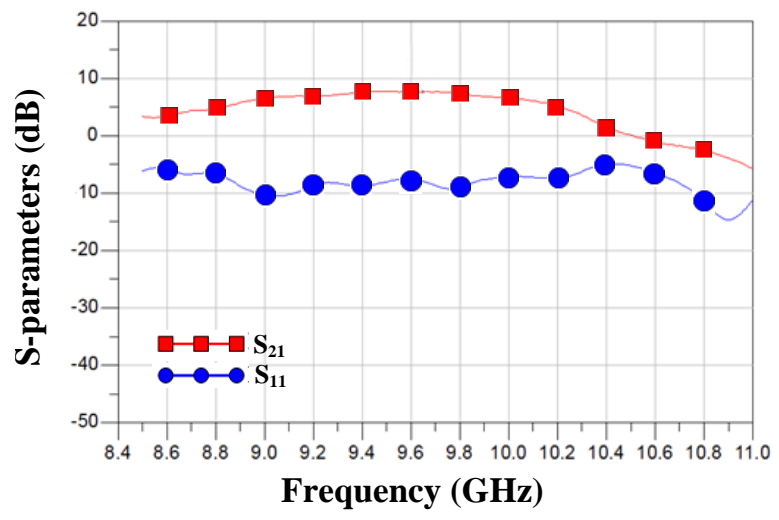

(b) Measured small signals

Figure 14: Measured small signal parameters of the proposed $\mathrm{GaN}$ high-power amplifier.

the operating temperature is still above the room temperature, which results the low PAE. Fortunately, in the future, heat pipes with heat sinks on the satellite will replace the used heat sinks with air blasts. The PAE will be higher than the measured results nowadays.

\section{Conclusion}

In this paper, we present a $\mathrm{GaN}$ high power amplifier using hybrid power combining technique, which is composed of PCB circuits and magic-T waveguides. By using PCB methods, the combining structure of 4-way GaN HEMTs can be compact. Moreover, two PCB circuits mounted on each side of heat sinks are combined by magic-T waveguides and cooled by air blasts. The $3 \mathrm{D}$ structure make the performance of power handling increased. The proposed GaN HPA exhibits the output power over $200 \mathrm{~W}$ and is a successful prototype for SAR applications. On the satellite, a compact 2500 W HPA can be made by combined several sets of the proposed HPA.

\section{Acknowledgements}

This work was supported by the National Space Organization (NSPO), Taiwan, under Contract NSPO-S104094. This work was also partially supported by the

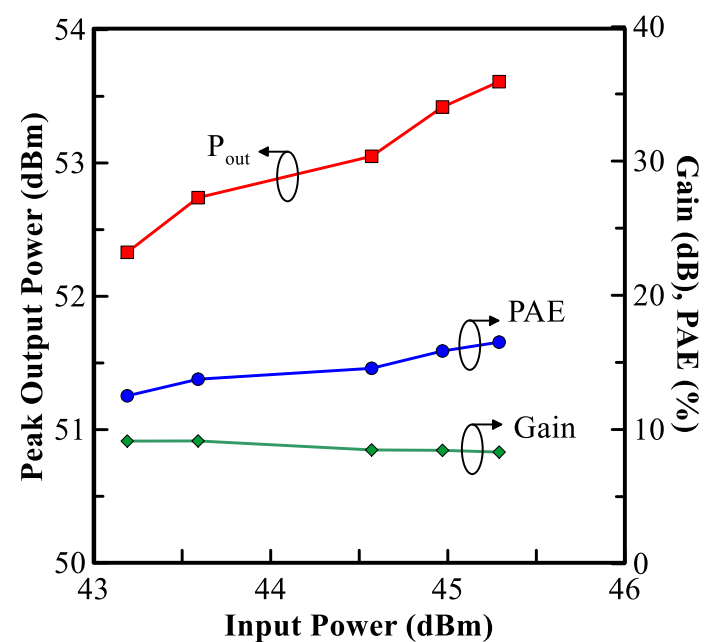

(a) $9.5 \mathrm{GHz}$

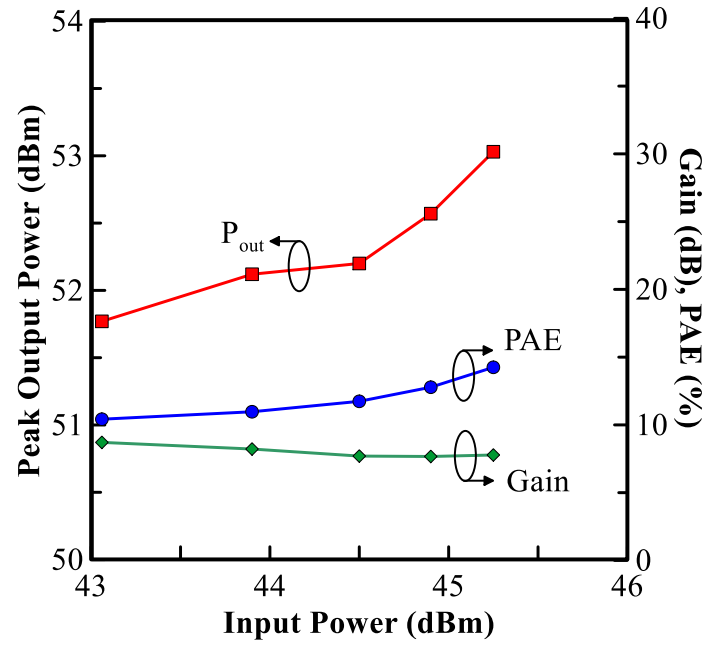

(b) $9.65 \mathrm{GHz}$

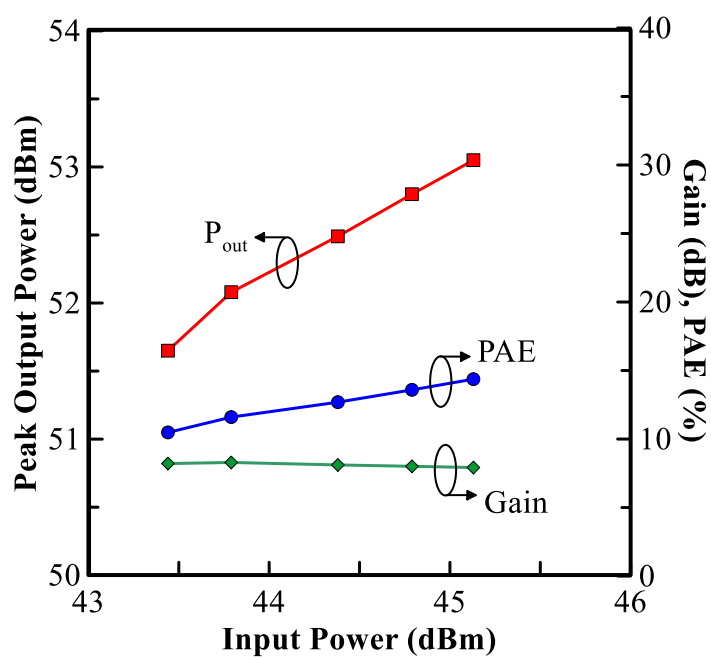

(c) $9.8 \mathrm{GHz}$

Figure 15: Measured peak output power, PAE, and power gain. 
"Center for mmWave Smart Radar Systems and Technologies" under the Featured Areas Research Center Program within the framework of the Higher Education Sprout Project by the Ministry of Education (MOE), and partially supported under MOST 107-3017-F-009-001, in Taiwan.

\section{References}

[1] E. Kuang, S. Naqvi, T. Davis, G. Kerslick, J. Nation, L. Schächter, Ge. Zhang, High power X-band microwave TWT amplifiers, 10 ${ }^{\text {th }}$ Int. Conf. High-Power Particle Beams, San Diego, CA, USA, pp. 877-880, June 1994.

[2] M. Forouzanfar, R. Feghhi, M. Joodaki, An 8.8-9.8 GHz $100 \mathrm{~W}$ hybrid solid state power amplifier for high power applications, 22 $2^{\text {nd }}$ Iranian Conf. Electrical Engineering (ICEE), Tehran, pp. 433-437, May 2014.

[3] H. Watanabe, O. Ceylan, H. Saito, A. Tomiki, H. Nunomura, O. Shigeta, N. Iwakire, T. Shinke, T. Fukami, High-efficiency $\mathrm{X}$ Band GaN power amplifier for small satellite downlink system, IEEE MTT-S Int. Microw. Symposium Digest (IMS), Seattle, WA, pp.1-4, June 2013.

[4] M. Casto, M. Lampenfeld, P. Jia, 100W X-band GaN SSPA for medium power TWTA replacement, Wireless Microw. Tech. Conf. (WAMICON), Clearwater Beach, FL, pp. 1-4, April 2011.

[5] K. Kanto, A. Satomi, Y. Asahi, Y. Kashiwabara, K. Matsushita, K. Takagi, An X-band 250W solid-state power amplifier using GaN power HEMTs, IEEE Radio and Wireless Symposium, Orlando, FL, pp. 77-80, 2008.

[6] P.G. Courtney, T. Tran, C. Bartak, C. Behan, P. Jia, High efficiency $80 \mathrm{~W}$ X-band power amplifier using coaxial waveguide spatial power combining technique, IEEE MTT-S Int. Microw. Symposium Digest (IMS), Anaheim, CA, USA, pp. 1396-1399, May 2010.

[7] U. K. Mishra, P. Parikh, Y. F. Wu, AlGaN/GaN HEMTs-an overview of device operation and applications, Proceeding of IEEE, vol. 90, no. 6, pp. 1022-1031, 2002.

[8] R. J. Trew, G. L. Bilbro, W. Kuang, Y. Liu, H. Yin, Microwave AlGaN/GaN HFETs, IEEE Microwave Magazine, vol. 6, no. 1, pp. 56-66, 2005.

[9] J. Wurfl, R. Behtash, R. Lossy, A. Liero, W. Heinrich, G. Trankle, K. Hirche, G. Fischer, Advances in GaN-based discrete power devices for L- and X-band applications, $1^{s t}$ European Microwave Integrated Circuits Conference, Manchester, pp. 490-492, 2006.

[10] S. Piotrowicz, E. Morvan, R. Aubry, S. Bansropun, T. Bouvet, E. Chartier, T. Dean, O. Drisse, C. Dua, D. Floriot, M.A. diForte-Poisson, Y. Gourdel, A.J. Hydes, J.C. Jacquet, O. Jardel, D. Lancereau, J.O. Mc Lean, G. Lecoustre, A. Martin, Z. Ouarch, T. Reveyrand, M. Richard, N. Sarazin, D. Thenot, S.L. Delage, State of the art $58 \mathrm{~W}, 38 \%$ PAE X-band AlGaN/GaN HEMTs microstrip MMIC amplifiers, IEEE Compound Semiconductor Integrated Circuits Symposium, Monterey (CSIC), CA, pp. 1-4, 2008.

[11] CREE 50W GaN HEMT CGHV96050F2 Datasheet, Online: http://www.cree.com/ /media/Files/Cree/RF/Data\%20Sheets/C GHV96050F2.pdf. 